Original Article

\title{
Altered Co-contraction of Cervical Muscles in Young Adults with Chronic Neck Pain during Voluntary Neck Motions
}

\author{
Chin-Hsiu Cheng ${ }^{1,2)}$, Hsin-Yi Kathy Cheng ${ }^{3)}$, Carl Pai-Chu Chen ${ }^{4}$, Kwan-Hwa Lin ${ }^{5}, 6$, \\ Wen-Yu Liu' ${ }^{1)}$, Shwu-Fen Wang ${ }^{6,7)}$, Wei-Li Hsu ${ }^{6,7)^{*}}$, Yu-Fen Chuang ${ }^{1,2)}$ \\ 1) Department of Physical Therapy and Graduate Institute of Rehabilitation Science, College of \\ Medicine, Chang Gung University, Taiwan \\ 2) Healthy Aging Research Center, Chang Gung University, Taiwan \\ 3) Graduate Institute of Early Intervention, College of Medicine, Chang Gung University, Taiwan \\ 4) Department of Physical Medicine and Rehabilitation, Chang Gung Memorial Hospital at Linkou and \\ College of Medicine, Chang Gung University, Taiwan \\ 5) Department of Physical Therapy, Tzu Chi University, Taiwan \\ 6) School and Graduate Institute of Physical Therapy, College of Medicine, National Taiwan \\ University: 326 Floor 3rd, No.17, Xuzhou Rd., Zhongzheng District, Taipei City 100, Taiwan \\ 7) Physical Therapy Center, National Taiwan University Hospital, Taiwan
}

\begin{abstract}
Purpose] Muscle co-contraction is important in stabilizing the spine. The aim of this study was to compare cervical muscle co-contraction in adults with and without chronic neck pain during voluntary movements. [Subjects and Methods] Surface electromyography of three paired cervical muscles was measured in fifteen young healthy subjects and fifteen patients with chronic neck pain. The subjects performed voluntary neck movements in the sagittal and coronal plane at slow speed. The co-contraction ratio was defined as the normalized integration of the antagonistic electromyography activities divided by that of the total muscle activities. [Results] The results showed that the co-contraction ratio of patients was greater during flexion movement, lesser during extension movement, slightly greater during right lateral bending, and slightly lesser during left lateral bending compared with in the controls. [Conclusion] The results suggested that neck pain patients exhibit greater antagonistic muscle activity during flexion and dominate-side bending movements to augment spinal stability, while neuromuscular control provides relatively less protection in the opposite movements. This study helps to specify the changes of the stiffness of the cervical spine in neck pain patients and provides a useful tool and references for clinical assessment of neck disorders.

Key words: Co-contraction, Chronic neck pain, Electromyography
\end{abstract}

(This article was submitted Oct. 4, 2013, and was accepted Nov. 10, 2013)

\section{INTRODUCTION}

Neck pain is a common disorder in the aged population. In young adults, the cumulative 1 year incidence of neck pain was estimated to be $16.4 \%{ }^{1)}$. Various physical, psychosocial, and sociodemographic factors have been reported to be associated with chronic neck pain ${ }^{2}$. Middle-aged subjects with chronic neck pain have shown dysfunction of kinesthetic sensibility characterized by increased movement irregularities ${ }^{3)}$ and movement errors ${ }^{4)}$ during reposition tasks. Subjects with chronic neck pain also showed abnormal cervical muscle recruitment patterns during dy-

*Corresponding author. Wei-Li Hsu (E-mail: wlhsu@ntu.edu. tw)

C2014 The Society of Physical Therapy Science. Published by IPEC Inc. This is an open-access article distributed under the terms of the Creative Commons Attribution Non-Commercial No Derivatives (by-ncnd) License $<$ http://creativecommons.org/licenses/by-nc-nd/3.0/>. namic and work-related tasks ${ }^{5}$. To prevent the progress of pain with age, the early detection of neck control problems in young patients with neck pain would be worthy of study.

Muscle co-contraction, the simultaneous activation of agonistic and antagonistic muscles, contributes to maintenance of spinal stability ${ }^{6}$. Since muscle stiffness increases with increased muscle activation associated with increasing effort, it is believed that co-contraction of muscles helps to stiffen and stabilize the spine ${ }^{7}$. Previous studies have shown that muscles exhibit higher activations and generate greater force during eccentric contractions than during concentric contractions $^{8)}$. Thus, co-contraction of antagonistic muscles is important to augment the stiffness of spine. Clarification of muscle co-contraction patterns can be helpful in understanding the control strategy of the central nervous system under different movement conditions and its links to neck disorders ${ }^{9}$.

Co-contraction of the extremities and trunk has been extensively studied ${ }^{10-12)}$. Muscle activity associated with voluntary co-contraction has been shown to increase joint 
stiffness. Researches have also indicated that muscle cocontraction can be affected by internal ${ }^{13,14)}$ and external ${ }^{15)}$ postural disturbances and can be affected by movement speeds ${ }^{16,17)}$. The regulation of co-contraction is presumably an efficient adjustment mechanism for spinal stability. Nevertheless, previous studies on the co-contraction of neck muscles were only conducted under isometric contraction in a neutral posture ${ }^{18)}$, and there are no studies related to the co-contraction pattern of patients with chronic neck pain.

The purpose of this study was to compare cervical muscle co-contraction during voluntary movements in healthy adults to that in patients with chronic neck pain. The cocontraction patterns were quantified by the electromyography-based (EMG-based) co-contraction ratio (CCR). Comparisons of the CCR between the two groups would reveal the characteristics of the neuromuscular control strategies, and could help to facilitate a specific training program for the treatment of neck disorders.

\section{SUBJECTS AND METHODS}

Fifteen subjects with a history of nontraumatic neck pain and fifteen asymptomatic age-matched subjects were recruited in this study. The subjects in the neck pain group (four males and eleven females) were between 20 and 28 years of age and had suffered from neck pain for at least six months (mean $41.4 \pm 43.8$ months). Subjects were excluded if they had either undergone cervical spine surgery or complained of any neurological signs. Asymptomatic subjects (six males and nine females) were between 19 and 28 years of age and were excluded if they had any history of neck pain or neck orthopedic disorders. All subjects were right-hand dominant. This study was approved by the institutional medical research ethics committee. Sufficient explanation about the experiment was given, and the experiment was conducted only with those who had consented to participation.

The average intensity of neck pain was measured by a 0-10 numerical rating scale (NRS), with 0 meaning "no pain" and 10 meaning "the worst possible pain imaginable." Patients also completed a self-administered questionnaire to determine their level of impairments resulting from neck pain by the neck disability index (NDI, total score of 50). Table 1 shows the duration of pain, average intensity of pain rated on the NRS, and perceived level of disability measured by the NDI for the neck pain group. The presence of cervical pain and dysfunction in all patients was examined by the same trained physiotherapist.

Surface EMG activities of the bilateral sternocleidomastoid (SCM), splenius capitis (SPL), and semispinalis capitis (SSC) were measured (Trigno Wireless, Delsys, Boston, MA, USA). The SCM muscles are the main neck flexors, and the SPL and SSC muscles are the main neck extensors in maintaining neck dynamic stability ${ }^{19)}$. These muscles are also the major muscles for lateral bending motion. The skin surface was shaved of hair and cleaned with alcohol swabs, and wireless EMG electrodes were applied. For the detailed placements of the electrodes on the SCM, SPL, and SSC muscles, please refer to our previous study ${ }^{20)}$. The Trigno Wireless system does not use a reference electrode.
Table 1. Descriptive statistics for the asymptomatic control subjects and patients with chronic neck pain

\begin{tabular}{lcc}
\hline & Control $(\mathrm{n}=15)$ & Patient $(\mathrm{n}=15)$ \\
\hline Age & $23.0 \pm 3.7$ & $23.3 \pm 2.8$ \\
Gender (male, female) & $(6,9)$ & $(4,11)$ \\
Height $(\mathrm{cm})$ & $165.4 \pm 8.8$ & $161.2 \pm 7.7$ \\
Weight $(\mathrm{kg})$ & $58.9 \pm 5.6$ & $54.3 \pm 8.3$ \\
History of pain (months) & - & $41.4 \pm 43.8$ \\
$\begin{array}{l}\text { Numerical rating scale } \\
\text { (score, } 0-10)\end{array}$ & - & $3.3 \pm 1.2$ \\
Neck disability index & & \\
(score, $0-50)$ & - & $6.5 \pm 3.4$ \\
\hline
\end{tabular}

An electrogoniometer (CXTLA02, Crossbow Technology, Inc., San Jose, CA, USA) attached at the top of the head was used to record the range of motion of the head synchronously with the EMG. The electrogoniometer traces the inclination to the gravity line and offers fast-response and high-resolution measurement $\left(0.1^{\circ}\right.$ over the range of $\left.\pm 90^{\circ}\right)$.

The recorded EMG signals were digitally band-pass filtered between $20 \mathrm{~Hz}$ and $450 \mathrm{~Hz}$, full-wave rectified, and smoothed with a low-pass filter (time constant of $100 \mathrm{~ms}$; Butterworth 4th-order). The high-pass cutoff frequency at $20 \mathrm{~Hz}$ reduced the noise sources from motion artifacts and ECG artifacts ${ }^{21)}$.

The subjects were asked to sit on a chair with their head positioned in a neutral position. They were instructed to perform two sessions of tasks sequentially. In the first session, the subject performed maximal voluntary isometric contraction (MVC) of the cervical muscles against a fixed surface for $3 \mathrm{~s}$ in the anterior, posterior, left, and right directions, respectively. There was a rest period of $2 \mathrm{~min}$ between each repetition to minimize the effect of fatigue. In the second session, the subject performed voluntary movements in the same four directions at slow movement speed. Each movement direction included two phases with the neutral position as the bench mark, i.e., from the neutral to terminal position, holding for $3 \mathrm{~s}$, and then from the terminal to neutral position. The terminal range of motion was reached when the subject felt mild resistance. Each movement was performed with a constant movement period of around $10 \mathrm{~s}$ to represent slow neck movement, which was selected to minimize the inertial interactions. Three trials of all the tasks were recorded and analyzed. To assure repeatability, all measurements were collected by the same trained physiotherapist.

For EMG analysis, the central 1-s EMG activities of three MVC trials were averaged as the reference activity for data normalization. The averaged EMG data were expressed as the normalized average integration of EMG activity (\%MVC). The six muscles in this study were attributed to either agonistic or antagonistic muscles. The antagonists were the bilateral SPL and SSC muscles in flexion, bilateral SCM muscles in extension, and the contralateral muscles in lateral bending (i.e., right side SCM, SPL, and SSC muscles during left lateral bending, and the left side SCM, SPL, and SSC muscles during right lateral bending). 
Table 2. The magnitudes of the co-contraction ratios of the healthy control and neck pain patients during the sagittal and coronal plane movements. * Significant difference $(\mathrm{p}<0.05)$ between the control and patient groups

\begin{tabular}{lcccc}
\hline & $\begin{array}{c}\text { Flexion } \\
\text { (neutral to flexed) }\end{array}$ & $\begin{array}{c}\text { Flexion } \\
\text { (extended to neutral) }\end{array}$ & $\begin{array}{c}\text { Extension } \\
\text { (neutral to extended) }\end{array}$ & $\begin{array}{c}\text { Extension } \\
\text { (flexed to neutral) }\end{array}$ \\
\hline Control & $0.79 \pm 0.07$ & $0.62 \pm 0.13$ & $0.27 \pm 0.09$ & $0.19 \pm 0.05$ \\
Patient & $0.88 \pm 0.05^{*}$ & $0.71 \pm 0.08^{*}$ & $0.18 \pm 0.06^{*}$ & $0.11 \pm 0.05^{*}$ \\
& $\begin{array}{c}\text { Right side bending } \\
\text { (neutral to right end) }\end{array}$ & $\begin{array}{c}\text { Right side bending } \\
\text { (left end to neutral) }\end{array}$ & $\begin{array}{c}\text { Left side bending } \\
\text { (neutral to left end) }\end{array}$ & $\begin{array}{c}\text { Left side bending } \\
\text { (right end to neutral) }\end{array}$ \\
Control & $0.52 \pm 0.07$ & $0.42 \pm 0.07$ & $0.52 \pm 0.07$ & $0.41 \pm 0.08$ \\
Patient & $0.55 \pm 0.08$ & $0.47 \pm 0.08$ & $0.49 \pm 0.07$ & $0.40 \pm 0.08$ \\
\hline
\end{tabular}

The CCR was then calculated by the following equation:

$$
\mathrm{CCR}=\Sigma \mathrm{NAIEMG}_{\text {Anta }} / \Sigma \mathrm{NAIEMG}_{\text {Total }}
$$

The subscript "Anta" indicates the antagonists, and "Total" indicates all muscles. Details of the algorithm were described in our previous study ${ }^{22}$.

The one-sample Kolmogorov-Smirnov normality test was used to verify whether each measurement was normally distributed. The independent t-test was used to examine the CCR measurements. The significance level was set to 0.05 .

\section{RESULTS}

The mean age, body height, and weight were not significantly different between groups. The recruited patients presented mild to moderate neck pain (numerical rating scale: 2-6) and mild disability (neck disability index: 3-14) (Table 1). Compared with the numerical rating scale recorded before and after the tests, no subjects complained of augmented pain. The asymptotic significances of the KolmogorovSmirnov test for the measurements $(p>0.05)$ indicated that all measurements complied with the normal distribution.

The CCRs were highest during motion from the neutral to flexed position (ranging from 0.79 to 0.88 ), and lowest from the flexed to neutral position (ranging from 0.11 to 0.18 ) during the sagittal plane motion in both groups. Compared with the control group $(0.79 \pm 0.07$ and $0.62 \pm 0.13$ for motion from the neutral to flexed position and motion from the extended to neutral position, respectively), the patients particularly showed greater CCRs $(0.88 \pm 0.05$ and $0.71 \pm 0.08)$ during the flexion movement (all $\mathrm{p}<0.025$ ). In addition, the patients also showed lesser CCRs $(0.19 \pm 0.05$ and $0.11 \pm 0.05$ for motion from the neutral to extended position and motion from the flexed to neutral position, respectively) during the extension movement compared with those of the controls $(0.27 \pm 0.09$ and $0.18 \pm 0.06$, all $\mathrm{p}<0.004)$ (Table 2).

The CCR generally ranged from 0.41 to 0.55 during the coronal plane motion in both groups. Compared with the control group $(0.52 \pm 0.07$ and $0.42 \pm 0.07$ for motion from the neutral to right end position and motion from the left end to neutral position, respectively), the patients showed marginally significantly greater CCRs $(0.55 \pm 0.08$ and $0.47 \pm 0.08$, $\mathrm{p}=0.08$ and $\mathrm{p}=0.06$, respectively) during the right lateral bending movement. The patients also showed slightly lesser CCRs $(0.49 \pm 0.07$ and $0.40 \pm 0.08$ for motion from the neutral to left end position and motion from the right end to neutral position, respectively) during the left lateral bending movement compared with those of the controls $(0.52 \pm 0.07$ and $0.41 \pm 0.08, \mathrm{p}=0.08$ and $\mathrm{p}=0.10$, respectively) (Table 2).

\section{DISCUSSION}

The major findings for the young adults with chronic neck pain were that 1) patients demonstrated higher CCRs during flexion and right lateral bending than the asymptomatic controls and 2) patients demonstrated lower CCRs during extension and left lateral bending than the control group. The different CCR patterns between the two groups indicate how neuromuscular control changes the stiffness levels of the cervical spine in response to chronic neck disorder. The rationale for the altered co-contraction of cervical muscles in patients with chronic neck pain is discussed as below.

This study showed that the CCRs of the patients during flexion and right lateral bending were greater than those of the healthy adults. This indicated that the spinal stiffness of the patients is predominantly taken up from the muscle guarding phenomenon as well as possible proprioceptive deficits. Sjolander et al. found that jerky and irregular cervical movements are characteristic sensorimotor symptoms in chronic neck pain ${ }^{3}$. Our previous study also showed that the neck pain patients would have poor position sense acuity $^{20)}$. Thus, the greater CCRs during those movements could be attributed to a higher activation of the antagonists to augment the steadiness of the spinal movement. However, the high muscular contraction is at the cost of greater muscle fatigability ${ }^{23)}$ and spinal loads ${ }^{24)}$. Endurance exercises designed for those muscles would be suggested to reduce myoelectric manifestations of cervical muscles and to induce an improvement in pain and function of the subjects with chronic neck pain ${ }^{25,26)}$.

The second finding of this study was that patients demonstrated lower CCRs during extension and LLB than the control group. This indicated that their neck flexors as well as the muscles on the dominant side are not sufficiently activated. Together with the above statement that the antagonists were highly activated during flexion and right lateral bending, there seems to be quite an imbalance in neck muscle activations of chronic neck pain patients between flexion and extension as well as between right and left lateral bending. The results implied that neuromuscular control provides relatively less protection for neck pain patients especially during neck extension and left lateral bending. 
Abnormal activations of neck muscles or neuromuscular control errors could decrease the stiffness of the cervical spine and expose it to a less stable situation, and may be the reason why the chronic pain persists. It was therefore suggested that strengthening of the neck flexors as well as the muscles on the dominant side to maintain a normal level of cervical co-contraction could be important for the prevention of neck disorders.

As discussed above, the CCR evaluation in the two groups aided in identification of a risk factor for chronic neck pain, that is, inadequate agonist/antagonist coordination. The low-load craniocervical flexion exercise, which is designed to flex the upper cervical spine, was reported to improve the muscle coordination ${ }^{27)}$. Several studies also reported a reduction in neck pain with strengthening and endurance exercise of cervical muscles ${ }^{28,29)}$. Further studies are needed to verify the effect of training protocols.

Several methodological considerations for this study should be addressed. First, only the superficial muscle groups were examined in this study. The indwelling needle electrodes used to detect small and deep muscles were not considered, since such a method may induce anxiety in neck pain subjects or hinder head movements. Second, the subjects were instructed to perform movements at a constant period to ensure the consistency of the neck movements. Since this study focused on the investigation of voluntary movements, the subjects were not controlled by constant angular velocities using an isokinetic dynamometer device. Finally, the number of subjects was relatively small. Caution should be emphasized in generalizing the findings.

In conclusion, the results showed that the young adults with chronic neck pain exhibited altered muscle responses. This could be due to the proprioceptive deficits that resulted in greater antagonistic muscle activity to augment spinal stability. Meanwhile, certain muscles also demonstrated insufficient activations that expose the patients to a less stable situation. Future studies to provide more insights into those mechanisms that could lead to better evaluation of neck pain and the development of rehabilitative exercise programs are suggested.

\section{ACKNOWLEDGEMENTS}

The authors thank all the participants. This research was supported by the National Science Council (100-2314-B182-030), the Chang Gung Memorial Hospital Research Program (CMRPD190231, CMRPD1B0501), and National Taiwan University (NTU-CDP-102R7835).

\section{REFERENCES}

1) Croft PR, Lewis M, Papageorgiou AC, et al.: Risk factors for neck pain: a longitudinal study in the general population. Pain, 2001, 93: 317-325. [Medline] [CrossRef]

2) Chiu TT, Lam PK: The prevalence of and risk factors for neck pain and upper limb pain among secondary school teachers in Hong Kong. J Occup Rehabil, 2007, 17: 19-32. [Medline] [CrossRef]

3) Sjölander P, Michaelson P, Jaric S, et al.: Sensorimotor disturbances in chronic neck pain - range of motion, peak velocity, smoothness of movement, and repositioning acuity. Man Ther, 2008, 13: 122-131. [Medline] [CrossRef]
4) Lee HY, Wang JD, Yao G, et al.: Association between cervicocephalic kinesthetic sensibility and frequency of subclinical neck pain. Man Ther, 2008, 13: 419-425. [Medline] [CrossRef]

5) Johnston V, Jull G, Darnell R, et al.: Alterations in cervical muscle activity in functional and stressful tasks in female office workers with neck pain. Eur J Appl Physiol, 2008, 103: 253-264. [Medline] [CrossRef]

6) Lee PJ, Rogers EL, Granata KP: Active trunk stiffness increases with cocontraction. J Electromyogr Kinesiol, 2006, 16: 51-57. [Medline] [CrossRef]

7) Gardner-Morse MG, Stokes IA: Trunk stiffness increases with steadystate effort. J Biomech, 2001, 34: 457-463. [Medline] [CrossRef]

8) Gabriel DA, Kamen G, Frost G: Neural adaptations to resistive exercise: mechanisms and recommendations for training practices. Sports Med, 2006, 36: 133-149. [Medline] [CrossRef]

9) Crisco JJ, Panjabi MM, Yamamoto I, et al.: Euler stability of the human ligamentous lumbar spine. Part II: Experiment. Clin Biomech (Bristol, Avon), 1992, 7: 27-32. [Medline] [CrossRef]

10) Granata KP, Marras WS: The influence of trunk muscle coactivity on dynamic spinal loads. Spine, 1995, 20: 913-919. [Medline] [CrossRef]

11) Hubley-Kozey C, Earl EM: Coactivation of the ankle musculature during maximal isokinetic dorsiflexion at different angular velocities. Eur J Appl Physiol, 2000, 82: 289-296. [Medline] [CrossRef]

12) Klein CS, Rice CL, Marsh GD: Normalized force, activation, and coactivation in the arm muscles of young and old men. J Appl Physiol 1985, 2001, 91: 1341-1349. [Medline]

13) Granata KP, Orishimo KF: Response of trunk muscle coactivation to changes in spinal stability. J Biomech, 2001, 34: 1117-1123. [Medline] [CrossRef]

14) Granata KR, Bennett BC: Low-back biomechanics and static stability during isometric pushing. Hum Factors, 2005, 47: 536-549. [Medline] [CrossRef]

15) van Dieën JH, Kingma I, van der Bug P: Evidence for a role of antagonistic cocontraction in controlling trunk stiffness during lifting. J Biomech, 2003, 36: 1829-1836. [Medline] [CrossRef]

16) Croce RV, Miller JP: The effect of movement velocity and movement pattern on the reciprocal co-activation of the hamstrings. Electromyogr Clin Neurophysiol, 2003, 43: 451-458. [Medline]

17) Suzuki M, Shiller DM, Gribble PL, et al.: Relationship between cocontraction, movement kinematics and phasic muscle activity in single-joint arm movement. Exp Brain Res, 2001, 140: 171-181. [Medline] [CrossRef]

18) Choi H: Quantitative assessment of co-contraction in cervical musculature. Med Eng Phys, 2003, 25: 133-140. [Medline] [CrossRef]

19) Bernhardt $\mathrm{P}$, Wilke HJ, Wenger KH, et al.: Multiple muscle force simulation in axial rotation of the cervical spine. Clin Biomech (Bristol, Avon), 1999, 14: 32-40. [Medline] [CrossRef]

20) Cheng $\mathrm{CH}$, Wang JL, Lin JJ, et al.: Position accuracy and electromyographic responses during head reposition in young adults with chronic neck pain. J Electromyogr Kinesiol, 2010, 20: 1014-1020. [Medline] [CrossRef]

21) Clancy EA, Morin EL, Merletti R: Sampling, noise-reduction and amplitude estimation issues in surface electromyography. J Electromyogr Kinesiol, 2002, 12: 1-16. [Medline] [CrossRef]

22) Cheng $\mathrm{CH}$, Lin $\mathrm{KH}$, Wang JL: Co-contraction of cervical muscles during sagittal and coronal neck motions at different movement speeds. Eur J Appl Physiol, 2008, 103: 647-654. [Medline] [CrossRef]

23) Falla D, Rainoldi A, Merletti R, et al.: Myoelectric manifestations of sternocleidomastoid and anterior scalene muscle fatigue in chronic neck pain patients. Clin Neurophysiol, 2003, 114: 488-495. [Medline] [CrossRef]

24) Granata KP, Marras WS: Cost-benefit of muscle cocontraction in protecting against spinal instability. Spine, 2000, 25: 1398-1404. [Medline] [CrossRef]

25) Ylinen J, Takala EP, Kautiainen H, et al.: Effect of long-term neck muscle training on pressure pain threshold: a randomized controlled trial. Eur J Pain, 2005, 9: 673-681. [Medline] [CrossRef]

26) Falla D, Jull G, Hodges $P$, et al.: An endurance-strength training regime is effective in reducing myoelectric manifestations of cervical flexor muscle fatigue in females with chronic neck pain. Clin Neurophysiol, 2006, 117: 828-837. [Medline] [CrossRef]

27) Falla D, Jull G, Russell T, et al.: Effect of neck exercise on sitting posture in patients with chronic neck pain. Phys Ther, 2007, 87: 408-417. [Medline] [CrossRef]

28) Bronfort G, Evans R, Nelson B, et al.: A randomized clinical trial of exercise and spinal manipulation for patients with chronic neck pain. Spine, 2001, 26: 788-797, discussion 798-799. [Medline] [CrossRef]

29) Ylinen J: Physical exercises and functional rehabilitation for the management of chronic neck pain. Eura Medicophys, 2007, 43: 119-132. [Medline] 